\title{
One-year results of intravitreal ranibizumab combined with reduced-fluence photodynamic therapy for polypoidal choroidal vasculopathy
}

This article was published in the following Dove Press journal:

Clinical Ophthalmology

28 January 2014

Number of times this article has been viewed

\section{Madoka Sakurai \\ Takayuki Baba \\ Masayasu Kitahashi \\ Hirotaka Yokouchi \\ Mariko Kubota-Taniai \\ Guzel Bikbova \\ Toshiyuki Oshitari \\ Shuichi Yamamoto}

Department of Ophthalmology and Visual Science, Chiba University

Graduate School of Medicine, Chiba, Japan
Correspondence: Takayuki Baba Department of Ophthalmology and Visual Science, Chiba University Graduate School of Medicine, I-8-I Inohana, Chuo-ku, Chiba 260-8670, Japan

Tel +8I 432262124

$\mathrm{Fax}+81432244162$

Email babatakayuki@nifty.com
Purpose: To compare the 1-year results of intravitreal ranibizumab combined with reduced-fluence photodynamic therapy (RF-PDT) to intravitreal ranibizumab (IVR) alone for eyes with polypoidal choroidal vasculopathy (PCV).

Methods: We reviewed the medical records from 47 consecutive patients with PCV (47 naïve eyes). Seventeen eyes from 17 patients had one IVR treatment combined with RF-PDT followed by two additional IVR treatments (combined group), and 30 eyes from 30 patients were treated with 3 monthly IVR treatments (IVR group). All eyes had a follow-up period of at least 12 months.

Results: At 12 months, the mean logarithm of the minimal angle of resolution (logMAR) bestcorrected visual acuity (BCVA) significantly improved from 0.55 to $0.38 \log$ MAR units in the combined group $(P=0.041)$ but did not change significantly in the IVR group $(P=0.371)$. The central foveal thickness (CFT) was significantly thinner in both groups at 6 months $(P<0.01)$. Additional IVR injections were required less frequently in the combined group $(n=3 ; 17 \%)$ than in the IVR group ( $\mathrm{n}=16 ; 53 \%)$ during the 12 month follow-up $(P=0.029)$.

Conclusion: The IVR and RF-PDT combination led to significant BCVA improvements and required fewer additional IVR treatments for at least 12 months in eyes with PCV.

Keywords: intravitreal ranibizumab, reduced-fluence photodynamic therapy, polypoidal choroidal vasculopathy

\section{Introduction}

Exudative age-related macular degeneration (AMD) is a leading cause of legal blindness in the elderly population in developed countries including Japan. Polypoidal choroidal vasculopathy $(\mathrm{PCV})$ is a subtype of exudative AMD and is characterized by branching vascular networks with terminal polypoidal lesions. ${ }^{1-5}$ Maruko et al reported that PCV accounts for more than half of Japanese patients diagnosed with exudative AMD, ${ }^{6}$ and two studies have reported that the incidence of PCV in Japanese patients was higher than in Caucasians. ${ }^{5,7}$

Many treatment modalities have been shown to be effective for PCV, however the best treatment for PCV has not been established. Recently, vascular endothelial growth factor (VEGF) has been reported to be associated with the pathogenesis of PCV, 8,9 and intravitreal injections of ranibizumab, a monoclonal antibody Fab fragment of VEGF, has become a standard treatment for PCV. ${ }^{10-12}$ Hikichi et al reported that three monthly intravitreal ranibizumab (IVR) injections led to a regression of the exudative changes and an improvement in the best-corrected visual acuity (BCVA) in patients with PCV. However, the polypoidal lesions disappeared in only $26 \%$ of the eyes. ${ }^{13}$ 
These findings indicate that IVR monotherapy might have limited effectiveness in eyes with PCV. ${ }^{14-16}$

Photodynamic therapy (PDT) with verteporfin has also been shown to be an effective treatment for PCV. ${ }^{17-23}$ The Japanese Age-Related Macular Degeneration Trial (JAT) reported that PDT significantly improved BCVA, and the improvement was maintained for up to 12 months in Japanese patients with PCV. ${ }^{24}$ However, PDT induced choroidal ischemia, which can lead to an increase in VEGF expression. ${ }^{8,9,25}$ PDT also had vision threatening side effects such as the induction of severe subretinal hemorrhage and thrombosis of the choriocapillaris. ${ }^{26-29}$

Because of these side effects, Michels et al examined the effects of reduced-fluence (RF)-PDT and reported that it was less damaging to the choriocapillaris than standard-fluence (SF)-PDT. ${ }^{30}$ Yamashita et al reported that RF-PDT was an effective and safe treatment for PCV. ${ }^{31}$ Several investigators have reported the effectiveness of SF-PDT combined with anti-VEGF agents for PCV. ${ }^{32-34}$ However, there have been no reports comparing the effects of IVR combined with RF-PDT to IVR alone.

Thus, the purpose of this study was to evaluate the efficacy and safety of combined IVR and RF-PDT. To accomplish this, we performed combined IVR and RF-PDT in one group of PCV patients and compared the functional and morphological changes to IVR monotherapy.

\section{Patients and methods}

We reviewed the medical records from 47 consecutive patients with PCV (47 eyes) treated at the Chiba University Hospital from April 2009 through March 2011. This study was approved by the Institutional Review Board of Chiba University Graduate School of Medicine. All procedures conformed to the tenets of the Declaration of Helsinki, and patients were informed of the aim of the study and written consent was obtained from all.

All 47 patients were Japanese ( 33 men, 14 women), and their mean age was $74.2 \pm 0.98$ years with a range of 58 to 90 years. The inclusion criteria were the presence of PCV observed by ophthalmoscopy or fundus angiography, active PCV region with hemorrhage and exudation, no previous treatments, and baseline decimal visual acuity better than 0.1 . All cases were followed for at least 12 months.

The clinical diagnosis of PCV was based on funduscopic examinations which showed subretinal reddish-orange spheroidal lesions or the presence of polypoidal vascular lesions including branching vascular networks in the indocyanine green angiograms (ICGA). ${ }^{35}$
Patients were divided into two treatment groups: a combined IVR + RF-PDT group and an IVR monotherapy group. Before August 2010, 30 eyes from 30 consecutive patients were treated with IVR alone and were placed in the IVR group. Thereafter, we switched the treatment to a combined IVR + RF-PDT and this group consisted of 17 eyes from 17 patients. Each had an IVR followed by RF-PDT 1 to 24 days later, followed by two additional IVR injections without PDT at 1 and 2 months after the first IVR. Most cases were treated within a week after the first IVR and only one eye received RF-PDT at 24 days after the first IVR. The IVR group consisted of 30 eyes from 30 patients who received 3 monthly IVR injections (monotherapy). In all cases, the dose of intravitreal ranibizumab (Lucentis; Novartis, Bulach, Switzerland) was $0.5 \mathrm{mg}$.

For RF-PDT, patients received an intravenous perfusion of verteporfin (Visudyne; Novartis Pharma, Tokyo, Japan) of $6 \mathrm{mg} / \mathrm{m}^{2}$ body surface area. Fifteen minutes later, the eye was irradiated by a diode laser $(689 \mathrm{~nm})$ for 42 seconds with a fluence of $50 \mathrm{~J} / \mathrm{cm}^{2}$ using the Visulas PDT system 690S (Carl Zeiss Meditec AG, Jene, Germany). We set the exposure time at half of the standard setting to reduce the total energy to half of that of SF-PDT. The area of the laser spot was determined by the size of the lesion on the ICGA, and the size covered the entire polypoidal lesion plus a margin of $1000 \mu \mathrm{m}$.

During the 12 month follow-up period, additional treatments were given if persistent polypoidal lesions were detected by ICGA, the BCVA decreased by at least one Snellen line with exudative changes at the macular detected by spectral-domain optical coherence tomography (SD-OCT; RTVue-100, OPTOVUE, CA, USA), an increase in central foveal thickness (CFT) of at least $100 \mu \mathrm{m}$, persistent macular fluid, and new macular hemorrhages. ${ }^{36}$ For retreatments, eyes in the combined group received RF-PDT if persistent polypoidal lesions were detected by ICGA and other cases received IVR alone.

At baseline, all patients had a complete ophthalmic examination including measurement of BCVA with a Snellen chart, SD-OCT, fluorescein angiography (FA), and ICGA with a fundus camera (TRC50; Topcon, Tokyo, Japan). The major outcomes measured were BCVA and CFT at 1, 3, 6, 9, and 12 months after the treatments and the number of additional injections of IVR during the 12-month follow-up. Systemic or ocular adverse events were also assessed. The grading of impaired perfusion of the choriocapillaris was based on the criteria reported by Michels et al. ${ }^{30}$ 
All values are presented as the means \pm standard error of the means (SEMs). The decimal BCVA was converted to the logarithm of the minimal angle of resolution (logMAR) units for the statistical analyses, and the changes in the BCVA were considered significant when the difference between the baseline BCVA and post-treatment BCVA was more than $0.3 \log$ MAR units. The significance of the differences in the findings was determined with the Wilcoxon's signed-rank test for the mean BCVA and CFT in each group. The MannWhitney $U$ test was used to compare two groups. Statistical significance was defined as $P<0.05$.

\section{Results}

The baseline demographics of the eyes in the combined IVR and RF-PDT group and the IVR alone group are shown in Table 1. There was no significant difference between the two groups except for the larger greatest linear dimension (GLD) in the combined group ( $P=0.004)$; the size of GLD was smaller than the limitation of PDT spot in all studied cases.

\section{Visual acuity}

At the baseline, the mean BCVA was 0.55 $\pm 0.05 \log$ MAR units in the combined group and $0.44 \pm 0.04$ in the IVR group $(P=0.053)$. At 12 months, the mean BCVA significantly improved to $0.38 \pm 0.07 \log$ MAR units $(P=0.041)$ in the combined group and was not significantly different in the IVR group at $0.43 \pm 0.08 \log$ MAR units $(P=0.371$; Figure 1$)$. Fifteen eyes (88\%) in the combined group and 26 eyes (87\%) in the IVR group had an improvement of $>0.3 \log$ MAR units or maintained their BCVA during the 12-month follow-up period. In these eyes, seven eyes (41\%) in the combined group and ten eyes (33\%) in the IVR group had an improvement of $>0.3 \log$ MAR units. The difference in BCVA

Table I Baseline characteristics of polypoidal choroidal vasculopathy

\begin{tabular}{llll}
\hline & IVR group & Combined group & P-value \\
\hline Number of eyes & 30 & 17 & Not applicable \\
Age (years) & $73.9 \pm 1.3$ & $74.8 \pm 1.4$ & 0.38 \\
Sex (female) & 10 & 4 & 0.52 \\
BCVA (logMAR) & $0.44 \pm 0.04$ & $0.55 \pm 0.05$ & 0.053 \\
CFT $(\mu \mathrm{m})$ & $349 \pm 24$ & $334 \pm 27$ & 0.538 \\
Greatest linear & $1,474 \pm 166$ & $2,576 \pm 243$ & 0.004 \\
dimension $(\mu \mathrm{m})$ & & &
\end{tabular}

Notes: Combined group: eyes treated with IVR combined with RF-PDT; IVR group: eyes treated with IVR only. Age, BCVA, CFT and greatest linear figures for IVR group and combined group are shown as mean \pm standard error.

Abbreviations: BCVA, best-corrected visual acuity; CFT, central foveal thickness; IVR, intravitreal injections of ranibizumab; logMAR, logarithm of the minimum angle of resolution; RF-PDT, reduced-fluence photodynamic therapy. between the two groups was not significant at 12 months $(P=0.546)$.

\section{Central foveal thickness}

At baseline, the mean CFT was $334 \pm 27 \mu \mathrm{m}$ in the combined group and $349 \pm 24 \mu \mathrm{m}$ in the IVR group $(P=0.538)$. At 12 months, the CFT significantly decreased to $208 \pm 17 \mu \mathrm{m}$ in the combined group $(P<0.01)$ and to $262 \pm 22 \mu \mathrm{m}$ in the IVR group $(P<0.01)$. The mean CFT was significantly thinner in the combined group than in the monotherapy group at 1 and 3 months $(P<0.01$ for both), but the difference was not significant at 12 months $(P=0.154$; Figure 2$)$.

\section{Number of retreatments}

Three patients in the combined group (17\%) and 16 patients in the IVR group (53\%) had additional IVR injections during the 12-month follow-up $(P=0.029)$. The mean number of additional injections of IVR were 0.4 times in the combined group and 1.3 times in the IVR group $(P=0.043)$.

In the combined group, additional RF-PDT was performed in two eyes and additional IVR injections were given in three eyes. Four of five eyes had retreatments over 6 months after the initiation of therapy. In the IVR group, additional IVR was given in 16 eyes including one eye with simultaneous pneumatic displacement for increased subretinal hemorrhage (Table 2).

\section{Angiography}

In the combined group, 14 of 17 patients were examined by FA and ICGA at 3 months after the RF-PDT to evaluate the polypoidal lesions and choroidal perfusion changes. The polypoidal lesions had disappeared in eleven of 14 eyes (79\%) which was confirmed by ICGA and two of these eyes were given additional RF-PDT which led to a resolution of the polypoidal lesions (Figure 3). All eyes had a mild to moderate non-perfused area of the choriocapillaris at 3 months after RF-PDT, and no severe changes were detected.

\section{Complications}

A subretinal hemorrhage developed in one patient in the combined group and two patients in the IVR group. One eye in the IVR group underwent additional IVR with pneumatic displacement, and in the other cases, the extent of hemorrhage was smaller than one disc area and only additional IVR was used. Mild vitreous hemorrhage was observed in one patient in the IVR group, and it was absorbed spontaneously. No systemic side effects were noted in either group. 


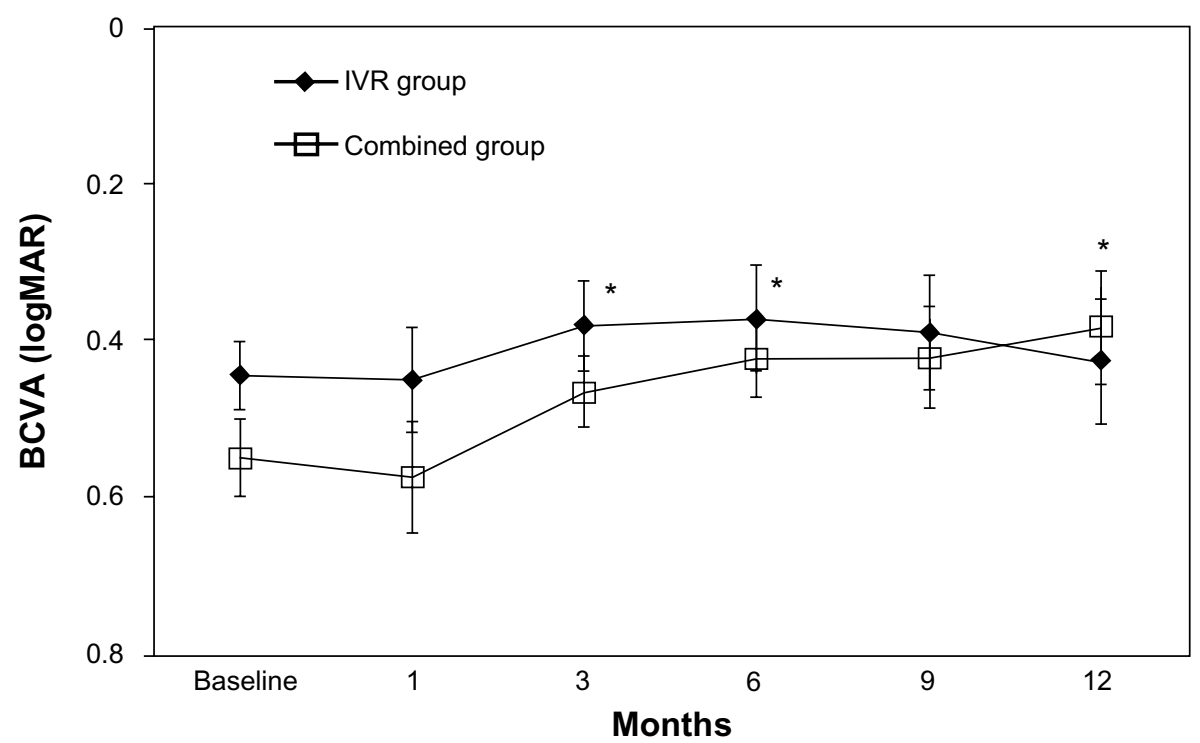

Figure I Changes in BCVA in the combined IVR with RF-PDT and the monotherapy IVR group. There was no significant difference in BCVA between the two groups at 12 months $(P=0.546)$

Note: $* P<0.05$.

Abbreviations: BCVA, best corrected visual acuity; IVR, intravitreal ranibizumab; logMAR, logarithm of the minimum angle of resolution; RF-PDT, reduced-fluence photodynamic therapy.

\section{Discussion}

Our results showed that the mean BCVA in $88 \%$ of eyes improved significantly or was maintained during the 12-month follow-up period in the combined therapy group. On the other hand, the mean BCVA did not change significantly after IVR monotherapy. The eyes in the combined therapy group also had a greater reduction in CFT than IVR alone and the number of eyes with a resolution of the polypoidal lesions was higher (79\%). The mean number of additional IVR injections was fewer in the combined group than in the monotherapy group (0.4 versus 1.3$)$. Thus, we conclude that a combination of IVR with RF-PDT is significantly more effective than IVR monotherapy for treating eyes with PCV.

Intravitreal ranibizumab injections have become a standard treatment for exudative AMD. ${ }^{10-12}$ Kokame et al reported

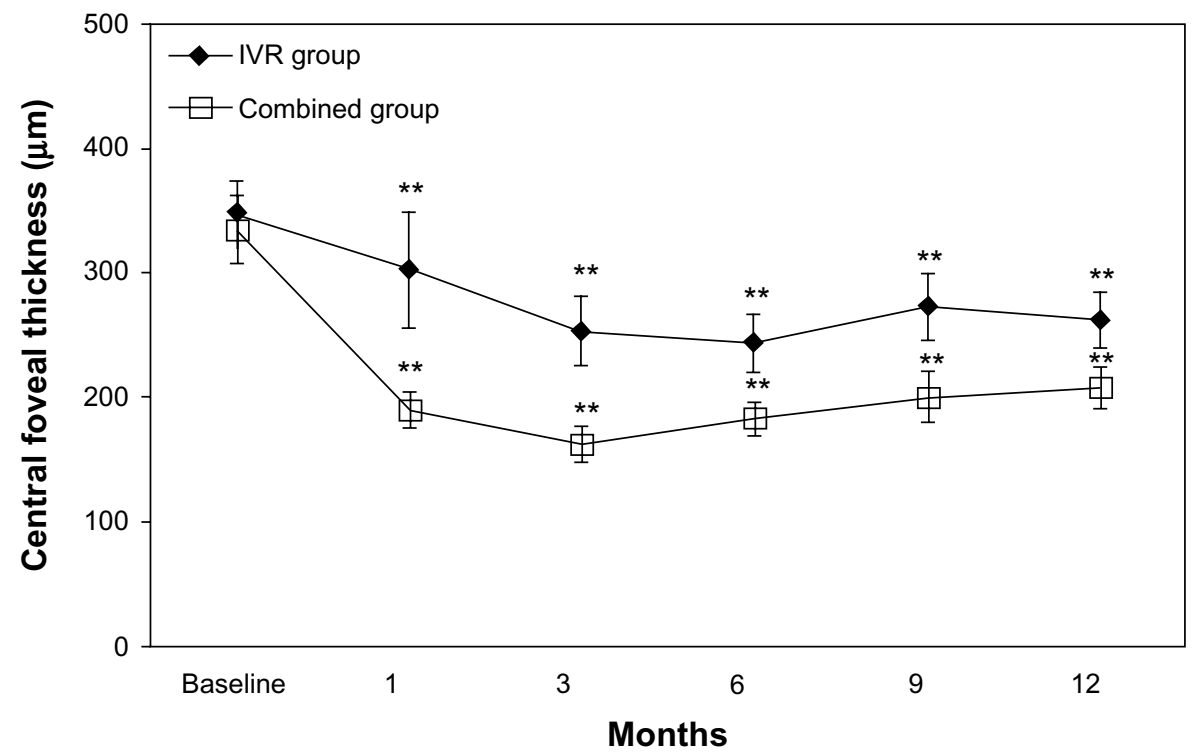

Figure 2 Changes in mean central foveal thickness. In the combined group, the mean central foveal thickness was significantly thinner than in the IVR group at I and 3 months $(P<0.0$ I for both), but not significant thereafter up to 12 months $(P=0.154)$.

Note: $* * P<0.01$.

Abbreviation: IVR, intravitreal ranibizumab. 
Table 2 Retreatments in the combined group and in the IVR group

\begin{tabular}{ll}
\hline & Number of eyes \\
\hline IVR group $(\mathrm{n}=30)$ & $16(53 \%)$ \\
IVR & $15(50 \%)$ \\
IVR + PD & $\mathrm{I}(3 \%)$ \\
Combined group $(\mathrm{n}=17)$ & $5(29 \%)$ \\
IVR & $3(18 \%)$ \\
RF-PDT & $2(11 \%)$ \\
\hline
\end{tabular}

Notes: Combined group: eyes treated with IVR combined with RF-PDT; IVR group eyes treated with IVR only.

Abbreviations: IVR, intravitreal injections of ranibizumab; PD, pneumatic displacement; RF-PDT, reduced-fluence photodynamic therapy.

that continuous monthly IVR stabilized vision but polypoidal lesions resolved in only $33 \%$ of eyes and branching vascular networks persisted in all eyes. ${ }^{15}$ Similarly, Hikichi et al reported that polypoidal lesions disappeared in only $26 \%$ of eyes after 3 monthly IVR injections, and the branching vessels responded poorly to the treatments. ${ }^{13}$ Continuous leakage from the persistent polypoidal lesions and branching vascular networks led to degeneration and atrophy of the retinal pigment epithelium (RPE) and eventual severe vision loss. Thus, ranibizumab alone may have limited effectiveness for PCV. ${ }^{14-16}$ We suggest that this may explain the lack of significant visual improvement at 12 months in our IVR monotherapy group.

The reason for the poor response of PCV to IVR may be because VEGF plays a less significant part in the pathogenesis of PCV than in AMD. ${ }^{8}$ As in occult choroidal neovascularizations (CNVs), the outer retinal barrier may obstruct ranibizumab from reaching the vascular lesion in eyes with PCV.
The eyes in the IVR monotherapy group had persistent exudation and required additional IVR injections suggesting an insufficient effect of ranibizumab for PCV. In contrast, PDT was effective in our patients which confirms similar results in earlier studies. ${ }^{32-34}$ Direct occlusion of the PCV lesion by PDT with verteporfin developed subsequent to the expression of low-density lipoproteins. ${ }^{37}$ PDT is effective because of the high penetration of verteporfin in vascular lesions.

Akaza et al reported that 29 of 35 eyes (83\%) had an improvement or maintenance of their baseline BCVA 6 months after SF-PDT for the retreatment of PCV, ${ }^{38}$ and Kurashige et al reported similar results in 35 of 41 eyes. $^{39}$ However, adverse events, such as the development of subretinal hemorrhage and thrombosis of the choriocapillaris have been reported to develop which led to visual reduction. ${ }^{17-23,26-29}$ Extensive subretinal hemorrhages after SF-PDT were reported in three eyes $(9 \%)$ by Akaza et a ${ }^{38}$ and one eye (5\%) by Chan et al. ${ }^{18}$ Kurashige et al ${ }^{13}$ reported that two eyes $(5 \%)$ developed vitreous hemorrhage requiring vitrectomy. On the other hand, Yamashita et al recently reported that RF-PDT was an effective and safe treatment for PCV. They reported that 26 of 28 eyes (93\%) had an improvement or maintained their BCVA during the 12 month follow-up period. In addition, no severe subretinal hemorrhage was observed, and there was only a mild transient choriocapillary nonperfusion suggesting that the damage to the choroid was less than after SF-PDT. ${ }^{31}$ We used RF-PDT instead of SF-PDT and found resolution of PCV in approximately $80 \%$ of the
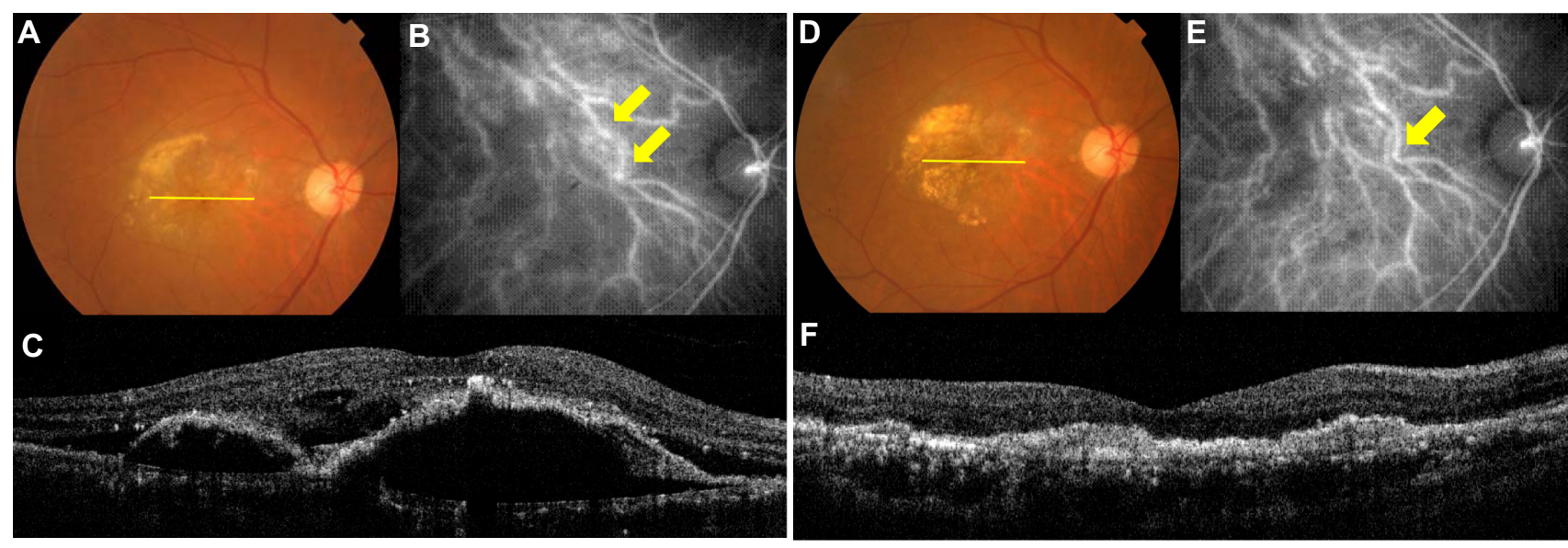

Figue 3 An 80-year-old Japanese man with PCV treated by IVR combined with RF-PDT.

Notes: (A) Fundus photograph before treatment showing subfoveal fibrous changes surrounded by subretinal hemorrhage and exudates; visual acuity was 0.2 . (B) Indocyanine green angiography showing branching vascular networks with polypoidal lesions (arrows). (C) Optical coherence tomography showing subretinal fluid and pigment epithelial detachment. (D) Fundus photograph at 3 months after combined therapy. The subretinal hemorrhage has been absorbed; the visual acuity is maintained at 0.2 . (E) Indocyanine green angiography showing no polypoidal lesions although the vascular networks remain (arrows). (F) Optical coherence tomography demonstrating no subretinal fluid or pigment epithelial detachment.

Abbreviations: IVR, intravitreal ranibizumab; PCV, polypoidal choroidal vasculopathy; RF-PDT, reduced-fluence photodynamic therapy. 
eyes after a single PDT session with fewer complications than previously reported. We reduced the exposure time to half of the standard setting because an earlier study reported that reduced time led to smaller hypofluorescent areas than with RF-PDT reduced energy. ${ }^{30}$ The incidence of primary closure of $\mathrm{CNV}$ and recurrences requiring additional treatments for 12 months were similar to that after reduced energy. ${ }^{40}$

Several investigators have reported that anti-VEGF agents reduce the development of exudative changes induced by the increased expression of VEGF shortly after PDT. ${ }^{15-22,25}$ Thus, Tomita et al reported that mean BCVA improved significantly and the polypoidal lesion disappeared completely in 19 of 24 eyes $(79 \%)$ at 3 months after SF-PDT with ranibizumab. ${ }^{32}$ Ruamviboonsuk reported that 7 of 12 eyes (58\%) had improved BCVA by 15 or more letters with PCV regression in $83 \%$ of eyes using a similar regimen. They also reported that combined therapy reduced the incidence of subretinal hemorrhage compared to PDT monotherapy for PCV. ${ }^{33}$ In our cases, the CFT in the combined group reduced soon after PDT and it was significantly thinner than in the IVR group for up to 3 months. There was a trend toward thinner CFT in the combined group although the difference was not significant at 12 months. The rapid reduction of the CFT instead of a transient increase in the combined group can be explained by the blocking of exudation after PDT. In addition, only one eye $(5 \%)$ developed subretinal hemorrhage which resolved without additional treatment.

The number of additional IVR injections was fewer in the combined therapy group. We hypothesize that this is because of the complete resolution of the PCV lesion by RF-PDT and less exudation soon after the RF-PDT reduced by IVR. The exudation after RF-PDT was probably also minimized by the milder damage caused by the RF-PDT. IVR monotherapy, on the other hand, required more injections due to persistent exudation from residual PCV lesions. Overall, we conclude that combined therapy with RF-PDT is better for treating PCV.

The limitations of this study are its retrospective nature, small sample size, short observation period of up to 12 months, and small number of eyes that had angiography to determine that the PCV had resolved. Additionally, the possibility of slight differences in the severity of the PCV between two groups at baseline may have affected improvements in visual acuity. However, our findings suggest that IVR combined with RF-PDT is effective for inducing regression of polypoidal lesions resulting in BCVA maintenance for up to 12 months. To confirm our data, a prospective, long-term study with a large number of eyes is necessary.

\section{Acknowledgments}

Medical writing assistance for this study was provided by Professor Duco Hamasaki, Bascom Palmer Eye Institute, University of Miami.

\section{Disclosure}

The authors report no conflicts of interest in this work.

\section{References}

1. Yannuzzi LA, Sorenson J, Spaide RF, Lipson B. Idiopathic polypoidal choroidal vasculopathy (IPCV). 1990. Retina. 2012;32 Suppl 1:1-8.

2. Yannuzzi LA, Ciardella A, Spaide RF, Rabb M, Freund KB, Orlock DA. The expanding clinical spectrum of idiopathic polypoidal choroidal vasculopathy. Arch Ophthalmol. 1997;115(4):478-485.

3. Spaide RF, Yannuzzi LA, Slakter JS, Sorenson J, Orlach DA. Indocyanine green videoangiography of idiopathic polypoidal choroidal vasculopathy. Retina. 1995;15(2):100-110.

4. Uyama M, Wada M, Nagai Y, et al. Polypoidal choroidal vasculopathy: natural history. Am J Ophthalmol. 2002;133(5):639-648.

5. Sho K, Takahashi K, Yamada H, et al. Polypoidal choroidal vasculopathy: incidence, demographic features, and clinical characteristics. Arch Ophthalmol. 2003;121(10):1392-1396.

6. Maruko I, Iida T, Saito M, Nagayama D, Saito K. Clinical characteristics of exudative age-related macular degeneration in Japanese patients. Am J Ophthalmol. 2007;144(1):15-22.

7. Uyama M, Matsubara T, Fukushima I, et al. Idiopathic polypoidal choroidal vasculopathy in Japanese patients. Arch Ophthalmol. 1999;117(8):1035-1042.

8. Tong JP, Chan WM, Liu DT, et al. Aqueous humor levels of vascular endothelial growth factor and pigment epithelium-derived factor in polypoidal choroidal vasculopathy and choroidal neovascularization. Am J Ophthalmol. 2006;141(3):456-462.

9. Matsuoka M, Ogata N, Otsuji T, Nishimura T, Takahashi K, Matsumura M. Expression of pigment epithelium derived factor and vascular endothelial growth factor in choroidal neovascular membranes and polypoidal choroidal vasculopathy. Br J Ophthalmol. 2004;88(6): 809-815.

10. Rosenfeld PJ, Brown DM, Heier JS, et al; MARINA Study Group. Ranibizumab for neovascular age-related macular degeneration. NEngl J Med. 2006;355(14):1419-1431.

11. Brown DM, Michels M, Kaiser PK, Heier JS, Sy JP, Ianchulev T; ANCHOR Study Group. Ranibizumab versus verteporfin photodynamic therapy for neovascular age-related macular degeneration: Two-year results of the ANCHOR study. Ophthalmology. 2009;116(1):57-65. e5.

12. Reche-Frutos J, Calvo-Gonzalez C, Donate-Lopez J, GarciaFeijoo J, Leila M, Garcia-Sanchez J. Short-term anatomic effect of ranibizumab for polypoidal choroidal vasculopathy. Eur J Ophthalmol. 2008;18(4):645-648.

13. Hikichi T, Ohtsuka H, Higuchi M, et al. Improvement of angiographic findings of polypoidal choroidal vasculopathy after intravitreal injection of ranibizumab monthly for 3 months. Am J Ophthalmol. 2010;150(5): 674-682. e1.

14. Stangos AN, Gandhi JS, Nair-Sahni J, Heimann H, Pournaras CJ, Harding SP. Polypoidal choroidal vasculopathy masquerading as neovascular age-related macular degeneration refractory to ranibizumab. Am J Ophthalmol. 2010;150(5):666-673.

15. Kokame GT, Yeung L, Lai JC. Continuous anti-VEGF treatment with ranibizumab for polypoidal choroidal vasculopathy: 6-month results. Br J Ophthalmol. 2010;94(3):297-301.

16. Rouvas AA, Papakostas TD, Ntouraki A, Douvali M, Vergados I, Ladas ID. Photodynamic therapy, ranibizumab, and ranibizumab with photodynamic therapy for the treatment of polypoidal choroidal vasculopathy. Retina. 2011;31(3):464-474. 
17. Spaide RF, Donsoff I, Lam DL, et al. Treatment of polypoidal choroidal vasculopathy with photodynamic therapy. Retina. 2002;22(5): 529-535.

18. Chan WM, Lam DS, Lai TY, et al. Photodynamic therapy with verteporfin for symptomatic polypoidal choroidal vasculopathy: oneyear results of a prospective case series. Ophthalmology. 2004;111(8): 1576-1584.

19. Quaranta M, Mauget-Faÿsse M, Coscas G. Exudative idiopathic polypoidal choroidal vasculopathy and photodynamic therapy with verteporfin. Am J Ophthalmol. 2002;134(2):277-280.

20. Otani A, Sasahara M, Yodoi Y, et al. Indocyanine green angiography: guided photodynamic therapy for polypoidal choroidal vasculopathy. Am J Ophthalmol. 2007;144(1):7-14.

21. Gomi F, Ohji M, Sayanagi K, et al. One-year outcomes of photodynamic therapy in age-related macular degeneration and polypoidal choroidal vasculopathy in Japanese patients. Ophthalmology. 2008;115(1):141-146.

22. Silva RM, Figueira J, Cachulo ML, Duarte L, Faria de Abreu JR, Cunha-Vaz JG. Polypoidal choroidal vasculopathy and photodynamic therapy with verteporfin. Graefes Arch Clin Exp Ophthalmol. 2005;243(10):973-979.

23. Eandi CM, Ober MD, Freund KB, Slakter JS, Yannuzzi LA. Selective photodynamic therapy for neovascular age-related macular degeneration with polypoidal choroidal neovascularization. Retina. 2007;27(7):825-831.

24. Japanese Age-Related Macular Degeneration Tial (JAT) Study Group. Japanese age-related macular degeneration trial: 1-year results of photodynamic therapy with verteporfin in Japanese patients with subfoveal choroidal neovascularization secondary to age-related macular degeneration. Am J Ophthalmol. 2003;136(6):1049-1061.

25. Schmidt-Erfurth U, Schlötzer-Schrehard U, Cursiefen C, Michels S, Beckendorf A, Naumann GO. Influence of photodynamic therapy on expression of vascular endothelial growth factor (VEGF), VEGF receptor 3, and pigment epithelium-derived factor. Invest Ophthalmol Vis Sci. 2003;44(10):4473-4480.

26. Hirami Y, Tsujikawa A, Otani A, et al. Hemorrhagic complications after photodynamic therapy for polypoidal choroidal vasculopathy. Retina. 2007;27(3):335-341

27. Schmidt-Erfurth U, Hasan T. Mechanisms of action of photodynamic therapy with verteporfin for the treatment of age-related macular degeneration. Surv Ophthalmol. 2000;45(3):195-214.

28. Ojima Y, Tsujikawa A, Otani A, Hirami Y, Aikawa H, Yoshimura N. Recurrent bleeding after photodynamic therapy in polypoidal choroidal vasculopathy. Am J Ophthalmol. 2006;141(5):958-960.
29. Lee YA, Yang CH, Yang CM, et al. Photodynamic therapy with or without intravitreal bevacizumab for polypoidal choroidal vasculopathy: two years of follow-up. Am J Ophthalmol. 2012;154(5):872-880. e2.

30. Michels S, Hansmann F, Geitzenauer W, Schmidt-Erfurth U. Influence of treatment parameters on selectivity of verteporfin therapy. Invest Ophthalmol Vis Sci. 2006;47(1):371-376.

31. Yamashita A, Shiraga F, Shiragami C, Ono A, Tenkumo K. Oneyear results of reduced-fluence photodynamic therapy for polypoidal choroidal vasculopathy. Am J Ophthalmol. 2010;149(3):465-471. e1.

32. Tomita K, Tsujikawa A, Yamashiro K, et al. Treatment of polypoidal choroidal vasculopathy with photodynamic therapy combined with intravitreal injections of ranibizumab. Am J Ophthalmol. 2012;153(1): 68-80. e1.

33. Ruamviboonsuk P, Tadarati M, Vanichvaranont S, Hanutsaha P, Pokawattana N. Photodynamic therapy combined with ranibizumab for polypoidal choroidal vasculopathy: results of a 1-year preliminary study. Br J Ophthalmol. 2010;94(8):1045-1051.

34. Ricci F, Calabrese A, Regine F, Missiroli F, Ciardella AP. Combined reduced fluence photodynamic therapy and intravitreal ranibizumab for polypoidal choroidal vasculopathy. Retina. 2012;32(7):1280-1288.

35. Japanese Study Group of Polypoidal Choroidal Vasculopathy. [Criteria for diagnosis of polypoidal choroidal vasculopathy]. Nihon Ganka Gakkai Zasshi. 2005;109(7):417-427. Japanese.

36. Fung AE, Lalwani GA, Rosenfeld PJ, et al. An optical coherence tomography-guided, variable dosing regimen with intravitreal ranibizumab (Lucentis) for neovascular age-related macular degeneration. Am J Ophthalmol. 2007;143(4):566-583.

37. Husain D, Miller JW, Michaud N, Connolly E, Flotte TJ, Gragoudas ES. Intravenous infusion of liposomal benzoporphyrin derivative for photodynamic therapy of experimental choroidal neovascularization. Arch Ophthalmol. 1996;114(8):978-985.

38. Akaza E, Mori R, Yuzawa M. Long-term results of photodynamic therapy of polypoidal choroidal vasculopathy. Retina. 2008;28(5):717-722.

39. Kurashige Y, Otani A, Sasahara M, et al. Two-year results of photodynamic therapy for polypoidal choroidal vasculopathy. Am J Ophthalmol. 2008;146(4):513-519.

40. Machida S, Nishimura T, Tamada K, Harada T, Kurosaka D. Macular function evaluated by focal macular electroretinograms after reduced fluence photodynamic therapy in eyes with polypoidal choroidal vasculopathy. Doc Ophthalmol. 2012;124(2):91-98.
Clinical Ophthalmology

\section{Publish your work in this journal}

Clinical Ophthalmology is an international, peer-reviewed journal covering all subspecialties within ophthalmology. Key topics include: Optometry; Visual science; Pharmacology and drug therapy in eye diseases; Basic Sciences; Primary and Secondary eye care; Patient Safety and Quality of Care Improvements. This journal is indexed on Submit your manuscript here: http://www.dovepress.com/clinical-ophthalmology-journal

\section{Dovepress}

PubMed Central and CAS, and is the official journal of The Society of Clinical Ophthalmology (SCO). The manuscript management system is completely online and includes a very quick and fair peer-review system, which is all easy to use. Visit http://www.dovepress.com/ testimonials.php to read real quotes from published authors. 